\title{
Well-being Indicators: a Review and Comparison in the Context of Italy
}

\author{
Silvia Facchinetti ${ }^{1}$ (D) Elena Siletti ${ }^{2}$ (D)
}

Accepted: 9 July 2021 / Published online: 21 July 2021

(c) The Author(s) 2021

\begin{abstract}
Interest in the well-being measurement is constantly increasing worldwide, especially due to the Stiglitz Commission suggestions, which opened several questions about its assessment and theoretical framework. This paper focuses on the Italian scenario due to the central role given to this topic by the Italian Parliament, which introduces equitable and sustainable well-being among the objectives of the government's economic and social policy. Significant differences exist among the proposed Italian well-being indices in terms of theoretical approach, statistical rigour and aims. We propose a detailed outline of these indices useful for policy-makers, practitioners, economists and statistics scholars, with the awareness that for a good analysis, a complete and conscious description of the data is the starting point to further improve their usefulness, to maximise their advantages and to cut down their limitations.
\end{abstract}

Keywords Well-being indices · Social indicators · Quality of life · Official statistics

\section{Background and Introduction}

The importance of well-being has been widely acknowledged, and its measurement is a matter that scholars have been tackling for a long time. A longtime used well-being measure is the Gross Domestic Product (GDP), which represents the market value of all goods and services produced by the economy, including consumption, investment, government purchases, private inventories, and the foreign trade balance. The advantages of GDP are manifold: it is able to connect goods and services with different nature, it presents a linear methodology, it is an objective and clear measure, and it is useful in international comparisons. However, issues and limitations using GDP have been widely discussed in the

Silvia Facchinetti

silvia.facchinetti@unicatt.it

Elena Siletti

elena.siletti@unimi.it

1 Department of Statistical Science, Università Cattolica del Sacro Cuore, Largo Gemelli, 1, 20122 Milano, Italy

2 Department of Economic and Political Sciences, Università della Valle d'Aosta, Località Le Grand-Chemin, 181, 11020 Saint-Christophe (AO), Italy 
literature. More than 50 years ago, Robert F. Kennedy, said: "Gross Domestic Product measures everything, in short, except that which makes life worthwhile". Focusing exclusively on GDP, we ignore the negative effects of economic growth on society, such as climate change and income inequality, nation's welfare or quality of life; as such, its use as well-being index can lead to misleading conclusions (Fleurbaey, 2009).

Several approaches have been developed across the years to overcome traditional economists' definition of well-being. (Sen, 2003) proposed an approach based on evaluating social change in terms of the richness of human life resulting from it. Following this proposal, different initiatives have been prospered. In 2007, the European Commission, European Parliament, Club of Rome, Organization for Economic Co-operation and Development (OECD), and World Wide Fund for Nature (WWF) hosted a conference titled "Beyond GDP" in order to identify the most appropriate indices and clarify how these indices can be integrated into the decision-making process and taken up for public debate. In 2009, the European Commission released its road map, the communication "GDP and beyond: Measuring progress in a changing world". On 14 September 2009, the Commission on the Measurement of Economic Performance and Social Progress (CMEPSP), generally referred to as the Stiglitz Commission ${ }^{1}$, submitted its report (Stiglitz et al., 2009) to the French President Sarkozy during a conference at the Sorbonne in Paris. They recommended broadening the scope of traditional indicators and suggested statisticians develop a system of indicators more inclusive of environmental and social aspects of progress, such as quality of life, social well-being, inequality and sustainability, parallel to its raw economic growth (OECD, 2013). Following this advice, several indices have been developed that represent both objective and subjective assessment, incorporating people's perception of quality of life (Fleurbaey, 2009), characterised by different structures, considering a great variety of domains and for many purposes. As international examples, we remember the Human Development Index, the Better Life Index, the Happy Planet Index, the Canadian Index of Well-being and the Gross National Happiness Index.

Alongside these traditional indices, some measures focused on life satisfaction and happiness, and based on big data, such as Twitter and Facebook, have recently proposed (Dodds et al., 2011; Curini et al., 2015; Schwartz et al., 2016). Moreover, other indices, especially in non-Western countries, give attention to spiritual well-being in life satisfaction, focussing on business and corporate context (Foster \& Wall, 2019; Khatri \& Gupta, 2017).

Altough there is great interest in well-being and its measure worldwide, in this paper we focus on the Italian scenario. This interest arises from the role given to this topic by Italian institutions: the Italian Parliament (law 163/2016) introduced equitable and sustainable well-being among the government's economic and social policy objectives (https://www. mef.gov.it/focus/Il-benessere-equo-e-sostenibile/). To our knowledge, this is an innovative inclusion in the economic-financial planning cycle that opens the way to a new vision of the relationship between public policies and the quality of life of citizens through a real assessment of the impact of public decisions on some specific indicators.

Moreover, in his conclusive speech at the VI National Conference ("Collective wellbeing and individual choices", Florence 12-14 December 2019) of the Italian Association for Quality of Life Studies (AIQUAV), Giancarlo Blangiardo, the President of the Italian National Institute of Statistics (ISTAT) confirmed the importance of the overall measures

\footnotetext{
1 The Stiglitz or Stiglitz, Sen, Fitoussi Commission was created by French President, Nicolas Sarkozy, and chaired by Nobel Prize-winning economist, Professor Joseph E. Stiglitz of Columbia University.
} 


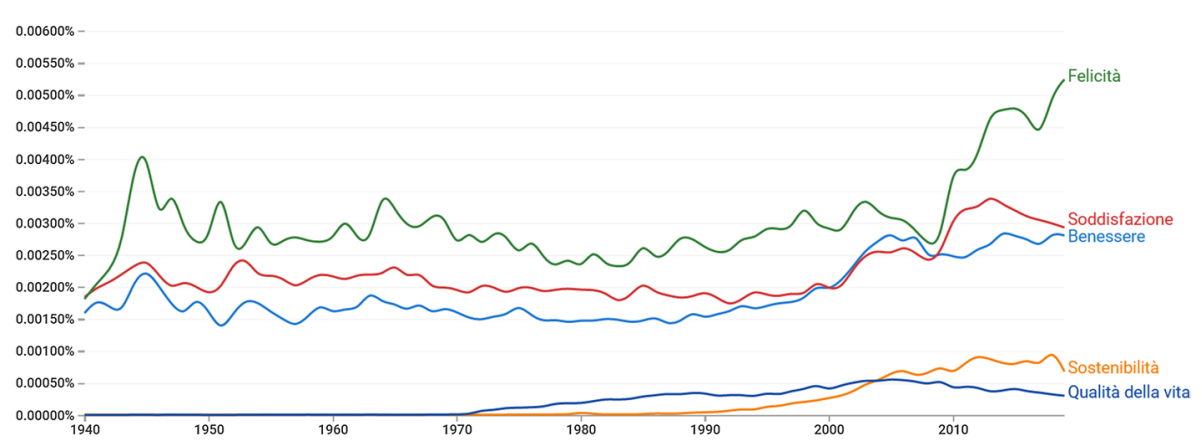

Fig. 1 Well-being related Italian terminology from 1940 to the last disposable year 2019

to define economics, political and social strategy plans, and disclosed the intent of his institution to provide domains and overall synthetic indices for the next releases of their wellbeing index.

In Italy, there are three principle well-being indices: the "Il Sole 24 Ore" Quality of Life index, which has a long history in Italian society, the Better Life Index, designed for comparison in international contexts, the recently proposed Equitable and Sustainable Well-Being Index, elaborated by a joint initiative of the National Committee for Economy and Labour (CNEL) and the ISTAT. These indices are general, not designed for specific groups (i.e. young people, elderly people, or workers), permitting to discussions within and between country comparisons, and used by institutions (national and international bodies).

For each index, we discuss its features, providing an objective evaluation of its structure, coverage, accuracy and availability. All of these characteristics are a challenge for a positive policy planning, an aware scientific use, and meaningful international comparison. The leading aim is not a stand-alone critique but also provides a detailed outline to multidisciplinary scholars, as sociologists, economists, psychologists and statisticians, with the awareness that for a good analysis, a complete and conscious description of the data is the starting point to further improve their usefulness.

The article is structured as follows. In Sect. 2, we report a detailed description of the principle Italian well-being indices, and in Sect. 3, a critical evaluation of their advantages and liabilities is proposed. The conclusion follows.

\section{The Well-being Indices Framework}

In Italy, as in several other countries, the interest in well-being measurement is constantly increasing, especially due to the Stiglitz Commission suggestions, which let open several questions about its assessment and theoretical framework. There are many Italian different terms spanning economic development concepts, generalised wealth, quality of life, etc. Following Barrington-Leigh and Escande (2018), in Fig. 1, the historical incidences of some relevant terms in Italian printed books. The well-being related words from the Italian dictionary that we considered in our Google N-grams (https://books.google.com/ngrams) are: "Benessere" = well-being, "Felicità" = happiness, "Qualità della vita" = quality of life, "Soddisfazione" = satisfaction and "Sostenibilità" = sustainability. 
The $y$-axis shows the percentage of all terms defined in the search, contained in Google sample of books written in Italian. Here, you can see that the use of the term "Qualità della vita" started to rise in the late 1970s, while the term "Sostenibilità", which appears to have been coined in the second half of the 1980s, overtook "Qualità della vita" around 2004. The words related to psychological dimension, including "Benessere", "Felicità", and "Soddisfazione" have similar time series, and they are quite constant, except for some peaks, that for "Benessere" and "Felicità" are particularly evident near the end of the Second World War in 1945. Moreover, from the beginning of the XXI century, we note an increase in the use of the words "Benessere" and "Soddisfazione" that seem to stabilise around an average level higher than in previous years. Otherwise, the term "Felicità" increases its use since the 2000s and reaches its maximum in 2019, confirming itself as the well-being related word most used in Italy.

Following the general interest and to face off the European and international comparisons, the evaluation of well-being in Italy has been evolved, but the characteristics of information sources are still not straightforward, and this issue is still an actual topic. Significant differences exist among the proposed well-being indices: in terms of theoretical approach that affects the choice of dimensions and variables, in terms of statistical rigour and, often, in the objectives for which they have been elaborated.

In order to perform an immediate, complete comparison between the indices, in the next sections we will describe in detail: the "Il Sole 24 Ore" Quality of Life index, the Better Life Index, the Equitable and Sustainable Well-Being Index and some marginal proposals from different sources.

\subsection{The "II Sole 24 Ore" Quality of Life Index-QoL}

The "Il Sole 24 Ore" Quality of Life Index (QoL) is the oldest well-being index proposed in Italy. Since 1990, the Italian business newspaper "Il Sole 24 Ore" annually publishes an index for all Italian provinces (107 in 2019). This is a strictly objective measure because it covers only material quality of life, and it avoids investigating subjective or perceived well-being. Nevertheless, for public opinion and media, it often is a benchmark indicator for Italian well-being.

It is defined along six relevant dimensions for which several representative indicators are considered. In 2016, the number of indicators for every topic increased from six to seven, but from 2019, this number further increased to fourteen or sixteen, achieving a total number of ninety indicators. The 2018 and 2019 general frameworks are reported in Tables 4 and 5 in Appendix. In the 2019 release (the last disposable), unfortunately, we quote that the sources and year references are not provided, the values are often rounded with an inadequate number of decimal digits, and it is impossible to download all data.

Nevertheless, by accessing the site of "Il Sole 24 Ore" dedicated to this initiative (http:// lab24.ilsole24ore.com/qualita-della-vita-2019/), it is possible to obtain, in addition to the values of the indicators, the scores assigned to each indicator, to the six domains, or to the overall index. With this detail, it is possible to obtain several different province rankings. In order to compute the rankings according to the single indicators, each variable is rated following its polarity interpretation (positive or negative). Until 2018, the province with the "best" indicator value is assigned a score equal to 1000 , while the remaining provinces receive a score proportional to the best one following this formula: 


$$
s_{i j}=\frac{x_{i j}}{x_{\max , j}} * 1000
$$

where, for the indicator $j, s_{i j}$ and $x_{i j}$ are the score and value for the province $i$, respectively, and $x_{\max , j}$ is the "best" value.

From 2019, the province with the "best" indicator value is assigned a score equal to 1000 , while the one with the "worst" indicator value is assigned a score equal to 0 . The remaining provinces receive a score linked to the extreme values following this formula:

$$
s_{i j}^{*}=\frac{x_{i j}-x_{\min , j}}{x_{\text {max }, j}-x_{\min , j}} * 1000
$$

where $x_{m i n, j}$ is the "worst" value. Moreover, the arithmetic mean is calculated within each domain, and the matching six rankings of the provinces are compiled. Finally, the overall mean between the dimensions is computed to achieve the overall index and the corresponding overall quality of life ranking (Lun et al., 2006).

The presence of the rankings for the Italian provinces is perhaps the most significant feature of the QoL, and this makes it so well considered by both public opinion and the media.

\subsection{The Better Life Index-BLI}

The BLI is a well-being index introduced in 2011 by the OECD (OECD, 2011) with the statistical report "How's Life?". This publication is released every two years and describes some of the essential aspects of life for people in OECD and partner countries. It is based on a multi-dimensional framework covering eleven dimensions in terms of material living conditions and quality of life (see Table 6 in Appendix). Data mostly come from official sources such as the OECD or National Accounts, United Nations Statistics, National Statistics Offices. Instead, some indicators are based on data from the Gallup World Poll: a division of the Gallup Organization that regularly conducts public opinion polls in more than 140 countries around the world. In each edition, looking at the OECD proposal, they consider how people's well-being is changing over time and how it is distributed among different population groups.

Each dimension is built on one to four indicators chosen on the basis of statistical criteria such as relevance and data quality, in consultation with OECD member countries, and are averaged with equal weights (data are for free download at https://stats.oecd.org/). At both national and regional levels, they consider 11 domains; nevertheless, the domain "Work-life balance" is considered only at the national level, while the "Accessibility of services" is considered at the regional level.

Moreover, going to its web platform (www.oecdbetterlifeindex.org) designed to visualise and compare the performances of the members, it is also possible to mix the set of dimensions, arbitrarily choosing the weights, in order to elaborate an index coherently with one's preferences (OECD, 2013). This option constitutes substantially relevant progress (Kasparian \& Rolland, 2012).

As the BLI gathers many indicators, expressed on different units, in order to compare and aggregate the values, a normalisation according to a standard formula similar to (2) is performed.

BLI provides details at the regional level, in an ad hoc initiative named "How's life in your region?" (www.oecdregionalwellbeing.org/). Its aim is to rank regions, see trends over 
time and understand how large disparities are across regions. This can be seen as a new offer to gauge what policies work and can empower a community to achieve higher wellbeing for its citizens.

For Italy, the OECD Regional initiative allows to measure well-being in its regions and compare it with 395 regions in 34 OECD countries. This edition adopts almost all the dimensions and similar indicators as in the national level, whenever data are available in a suitable format. ${ }^{2}$

In the November 2018 release, currently online as the latest disposable, they do not refer to a single period. They simply write about "first year available" and "last year available" without specifying, if not in the most specific material that is sometimes difficult to understand, the true reference for each country.

\subsection{The Equitable and Sustainable Well-Being Index-BES}

In 2013, following the suggestions of scholars related to the Stiglitz Commission movement (Stiglitz et al., 2009), a joint initiative of CNEL and ISTAT provided this innovative system of well-being measurements. The aim was to develop a collective definition of progress in Italian society and producing a shared set of indicators of the most relevant economic, social and environmental domains (Nissi \& Sarra, 2018). A conceptual and statistical similar BLI index, BES has a multi-dimensional nature and is nowadays the Italian benchmark for the annual quality of life evaluation.

The first edition was defined by more than 130 single indicators, according to twelve domains, for the twenty Italian regions. Each dimension, measured by 4 to 15 indicators, displays particular aspects of daily life. The full BES framework is reported in Table 7 in Appendix.

Including the last release, seven editions of the BES have been published. Since its initiation, it has been improved, giving composite indices for the topic dimensions and updating the underlined indicators. In the following descriptions, we will refer to the current edition that is released in December 2019 (ISTAT, 2019).

From 2013 to 2014, the only available aggregation form of the index was provided by IRES Piemonte (the Regional Institute for Economic and Social Research of Piemonte). Since 2015, ISTAT provided itself domain-specific composite indicators to different aggregation levels. In order to perform the synthetic indices, they adopt the Adjusted MazziottaPareto Index (AMPI et al., 2007, 2016). This approach consists of a min-max transformation of elementary indicators and their aggregation with the arithmetic average penalised by the horizontal variability of the same indicators. More formally, let $\mathbf{X}=\left\{x_{i j}\right\}$ be the matrix with $n$ rows (statistical units) and $m$ columns (individual indicators). According to the original direction of the indicator, the elements of the normalised matrix $\mathbf{R}=\left\{r_{i j}\right\}$ are:

$$
r_{i j}^{+}=\frac{x_{i j}-x_{\text {min } j}}{x_{\text {max }, j}-x_{\text {min }, j}} 60+70 \quad \text { or } \quad r_{i j}^{-}=\frac{x_{\text {max }, j}-x_{i j}}{x_{\max , j}-x_{\min , j}} 60+70
$$

where $x_{i j}$ is the value of individual indicator $j$ for the statistical unit $i, x_{\min , j}$ and $x_{\max , j}$ are the "goalposts" for the indicator $j$.

The AMPI is defined by:

${ }^{2}$ Some topics and regional indicators are not currently available as displayed in the last column of Table 6. 


$$
A M P I_{i}^{+/-}=M_{r_{i}} \pm S_{r_{i}} \cdot c v_{r_{i}}
$$

where $M_{r_{i}}$ and $S_{r_{i}}$ denote the mean and standard deviation of the normalised values of the $i$-th unit, respectively. The penalty is based on the coefficient of variation $c v_{r_{i}}=S_{r_{i}} / M_{r_{i}}$ that can be added or subtracted, depending on the nature of the phenomenon to be measured and hence on the direction of the individual indicators (De Mauro et al. 2011).

Due to the increased necessity to inform policy-makers about the perceived effects of local policies, in 2013 from a pilot initiative of the Province of Pesaro and Urbino the BES of the provinces has been proposed. It was developed thanks to the collaboration between the Coordination of Statistics Offices of the Italian Provinces (CUSPI) and ISTAT, with the aim to create a statistical information system for measuring equitable and sustainable well-being, in support of the strategic and operational planning of large area organisations. Following the pilot edition, other editions were published, since the last one in 2019 with 20 participating provinces ${ }^{3}$ and seven metropolitan cities ${ }^{4}$, this result is far from full coverage of the Italian provinces. This index is defined by a set of indicators, according to 11 domains, calculated homogeneously in all territories participating to the project, with a series of economic and demographic indicators.

Additionally, we remark that at the beginning of 2012, some Italian cities were involved in the UrBES project (The Equitable and Sustainable Well-Being in the cities (Ivaldi et al., 2014)), an important part of BES initiative measuring well-being at an urban level. The project began with a collaboration between the Municipality of Bologna and ISTAT, to locally apply the BES methodology. It is based on a subset of the BES indicators available at the municipal level to build tools that allow administrators and local communities to analyse in detail the local well-being of their territories. The 61 statistical indicators are divided into eleven domains. The development of the UrBES Project led to the production of two reports in 2013 and 2015. In fact, it is not a stand-alone project but has been included in the BES of the provinces, adding the metropolitan cities as described above.

\subsection{Other Proposals}

Following the demand for new well-being measures (Stiglitz et al., 2009), being able to fill the need for a local dimension (Bai et al., 2012; Banai \& Rapino, 2009) and reveal the active well-being process that rapidly changes over time, other initiatives must be remembered in the Italian context. In this review, we shortly cite two of them: the Regional Quality of Development Index and the Subjective Well-being index.

\subsubsection{The Regional Quality of Development Index-QUARS}

From 2003 to 2011, anticipating in part the work done with the BES, the Italian campaign "Sbilanciamoci!"5 proposed the QUARS to assess the quality of life for the Italian regions

\footnotetext{
${ }_{3}^{3}$ Alessandria, Ancona, Benevento, Cremona, Grosseto, Lecce, Lucca, Mantua, Matera, Parma, Pesaro e Urbino, Piacenza, Potenza, Ravenna, Rimini, Rovigo, Siena, Taranto, Treviso, and Vercelli.

4 Bari, Bologna, Florence, Genoa, Milan, Naples, and Rome.

5 "Sbilanciamoci" is a network of more than 40 Italian civil society organizations active at national level, whose aim is to building a society that considers the needs of citizens and the environment (Rondinella et al., 2014).
} 
(Segre et al., 2011). This composite index attempted to identify and connect the components of development quality based on environmental sustainability, promotion of rights and quality of life. It encompassed 45 variables divided into seven dimensions, all considered equally important: democratic participation, economy and labour, education and culture, environment, gender equity, health, rights and citizenship.

The selected variables that made up the index were all standardised, and a group mean was calculated for each dimension, while the final synthetic QUARS was obtained by aggregating the seven indices through a simple mean. Finally, it was centred around the zero mean, with positive values representing a score above the provinces' average, and negative values a score below it.

This initiative, besides several positive comments, was charged with some weaknesses (Burchi \& Gnesi, 2016). Briefly, it presented a lack of an adequate conceptual framework for the choice of indicators because the definition of quality of life is "limited by data availability" (Segre et al., 2011), and the authors followed a strictly empirical approach.

With the birth of the BES, this initiative expired, and its experience was combined in the novel ISTAT venture.

\subsubsection{The Social Well-being Index-SWBI}

Since 2012, an Italian team (Iacus et al., 2015) proposed to audit the subjective and perceived well-being revealed by a community through social networking and, especially, the microblogging service Twitter. This initiative was created for multiple reasons. First, the opportunity to exploit a new large amount of data that enabled a new dimension of social dynamics study, like never before (Pentland, 2014); additionally, the chance to deal with the information provided for free (or at an extremely low cost), and, more powerful, updated in real-time with a very interesting time-frequency; finally, the chance to fill the gap represented by the limited and undersized presence of subjective and perceived dimensions of well-being in official Italian statistics.

The Italian edition ${ }^{6}$ of the SWBI index is the result of a human Integrated Sentiment Analysis-iSA (Ceron et al., 2016) on tweets acquired via the public Twitter API, written in the Italian language and posted from Italy. This composite index consists of eight domains, inspired by the Better Life Index (BLI) initiative (New Economics Foundation, 2012), that concern three well-being areas: Personal well-being, Social well-being and Well-being at work.

Furthermore, it is important to notice that thanks to a share of the data, which include geo-reference information, it is possible to define the SWBI estimation at a local level, allowing both a provincial and regional proposal.

Although social media has recently been considered the largest available focus group in the world (Kwong et al., 2012; Hofacker et al., 2016), and they provide several advantages, it is important to remember that such information is not free of disadvantages. In order to be a Twitter user, one must overcome some blocks: to have Internet access, to open a Twitter account, and to actively use it. We remark on penetration data from the "We Are Social and Hootsuite's" report ("Digital in 2020", Jan 2020; available at http://wearesocial. com). Looking at the Italian experience, $82 \%$ has Internet access, and $58 \%$ has a social

\footnotetext{
${ }^{6}$ In addition to the Italian experience, also a Japan project has been performed, and some attempts have been sketched for other countries (Iacus et al., 2019).
} 
media account and makes active use of it. Even if the number of users is increasing with the passage of time, one of the main open issues linked to these concerns is the sampling bias. Since it is clearly not possible to renounce such an intense source of information, the full point is to use such data together with official statistics and not in replacement of them (Iacus et al., 2020).

\section{Discussing the Scenario of Well-being Indices}

Section 2 shows that well-being information actually provided for Italy has been improved according to the suggestions of the international scientific community. Despite all efforts, all the indices still presents several gaps. Table 1 displays a synthesis of their principle traits.

The three indices are annual, and this frequency could hide interesting temporal changes. Moreover, the subjective dimension is under-represented, as exemplification, focussing on the regional framework for QoL subjective indicators are unconsidered; for BLI, they represent only $7.7 \%$, and for BES, they correspond to $17.7 \%$. Looking at the geographical disaggregation level, QoL is defined only at the provincial level, BLI is computed at national and regional levels, BES is performed at the regional level, while the provincial level is only a pilot experience limited to a few provinces or cities, and the country values are simply the means of the regional values.

Following Hagerty et al. (2001) proposal and Stiglitz et al. (2009) suggestions, we propose an evaluation of the advantages and liabilities of the same indices. Table 2 summarises each index on the basis of the presence/absence of some criteria that will be highlighted in the next sections.

\section{Clear practical purpose of the index}

All the indices have a clear practical purpose. Especially, QoL was born with a press journalistic scoop purpose. Throughout the years, due to the initial absence of other institutional sources, it has become a benchmark of Italian well-being measure obviously for media, but also for practitioners and scholars (Lun et al., 2006), forgetting that the methodological aspect is often unrealised. For this, as an example, we underline the habits of this team to change the used indicators and the corresponding dominions in the different editions, despite their intent to keep the time-series information.

The BLI has been proposed with the final aim of comparing well-being in the different OECD countries or regions. This scope could be spoiled by the fact that for some countries or regions, the indicators correspond to different years, sometimes with a great delay. For example, looking at the "Dwellings without basic facilities" indicator, the value refers to 2016 for Luxembourg and the Netherlands, but to 2001 for Canada.

The BES's practical purpose is to support scholars and policy-makers with official statistics and methods to better understand the multifaceted well-being structure. The balance between the needs to lend useful information and the commitment to keep a methodological rigour has provided delay that, as an example, appears in the supply of a unique score or ranking.

\section{Public Policy-makers support}




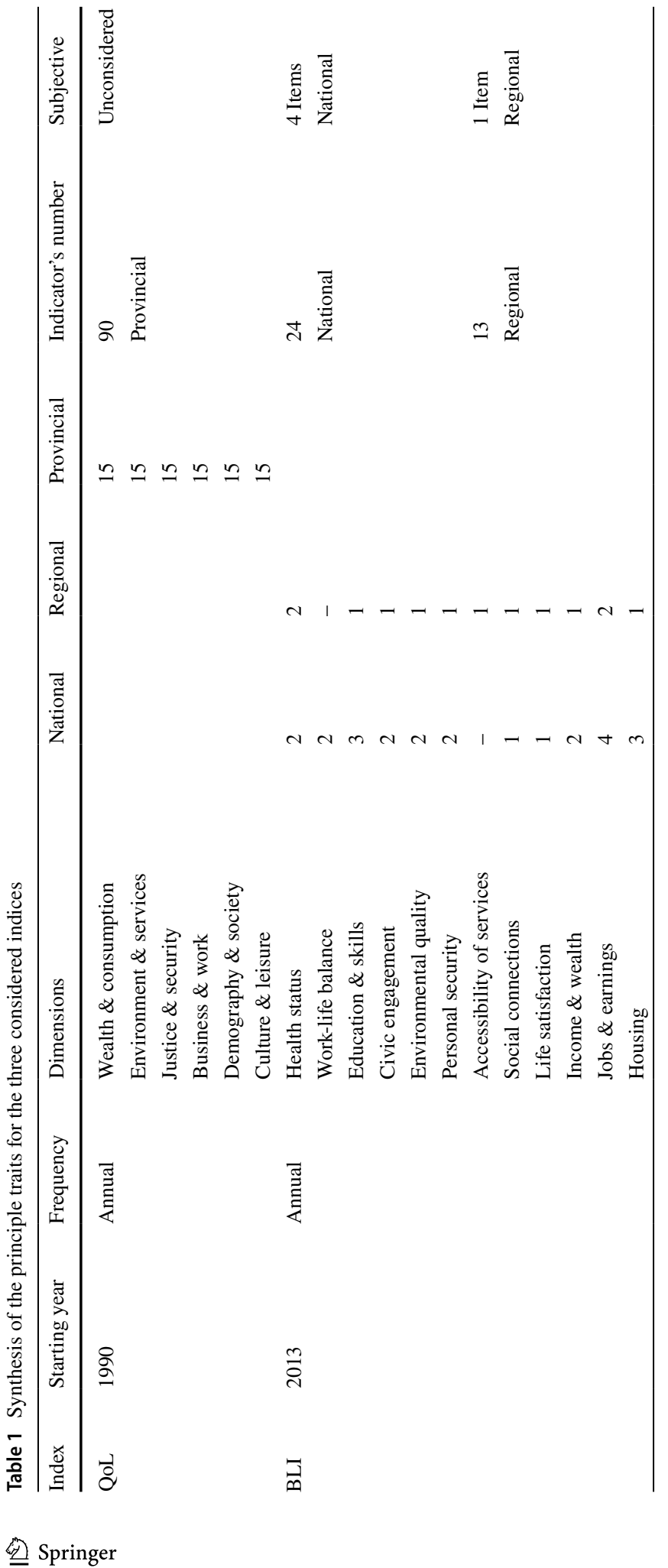




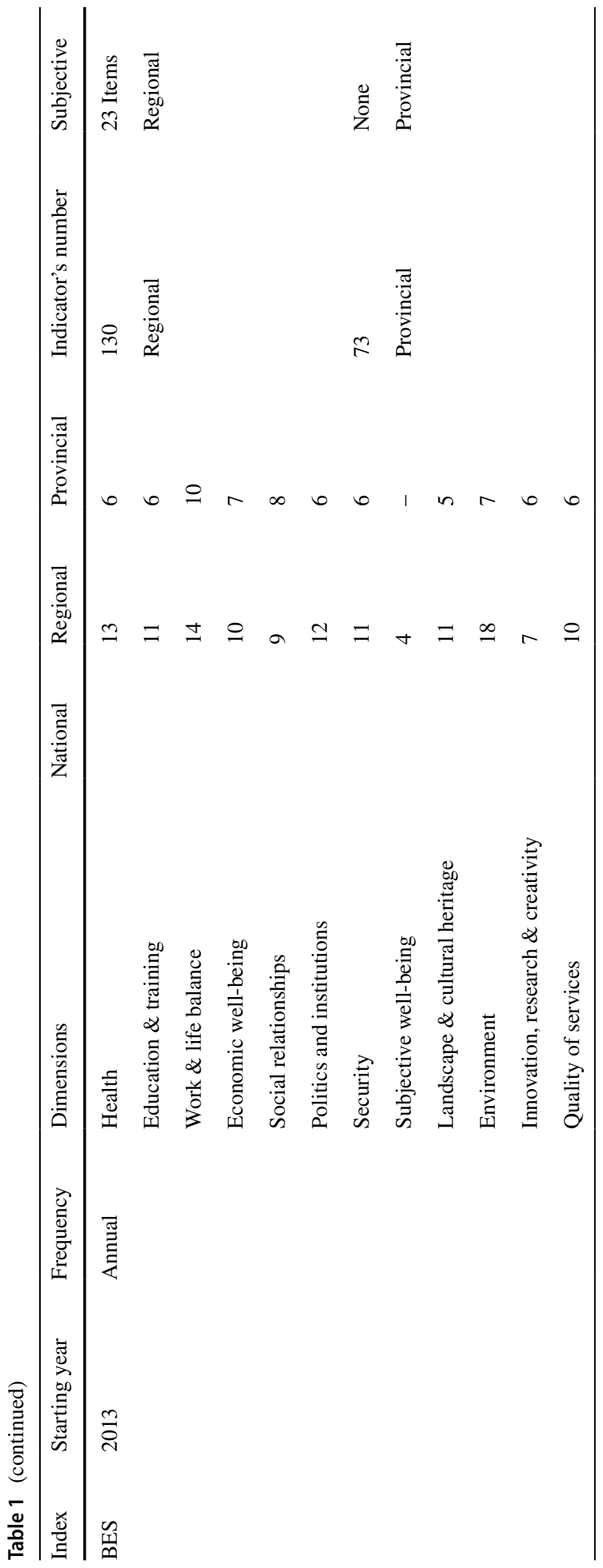


Table 2 Synthesis of the used evaluation criteria

\begin{tabular}{|c|c|c|c|}
\hline Criteria & QoL & BLI & BES \\
\hline 1. The index must have a clear practical purpose & $X$ & $X$ & $X$ \\
\hline \multicolumn{4}{|c|}{$\begin{array}{l}\text { 2. The index should help public policy-makers develop and assess programs at differ- } \\
\text { ent levels of aggregation: }\end{array}$} \\
\hline 2a. Provincial level-NUTS 3 & $\mathrm{X}$ & & $X^{*}$ \\
\hline 2b. Regional level-NUTS 2 & & $\mathrm{X}$ & $\mathrm{X}$ \\
\hline 2c. Country level & & $X$ & $\mathrm{X}^{*}$ \\
\hline
\end{tabular}

3. The index should be based on time series to allow periodic monitoring and control:

3a. Annual time series

$\mathrm{X}$

$\mathrm{X}$

3b. Semi-annual or with higher frequency time series

4. Multi-dimensional framework of the index

4a. Composite indices

4b. Synthetic indices

5. Each domain must be measured in both objective and subjective dimensions

\begin{tabular}{lll}
$X$ & $X$ & $X$ \\
$X$ & $X$ & $X^{*}$ \\
& $X^{*}$ & $X^{*}$ \\
\hline
\end{tabular}

The symbol " $\mathrm{X}$ " means the presence of the criteria, with a "*" means that is partially accomplished

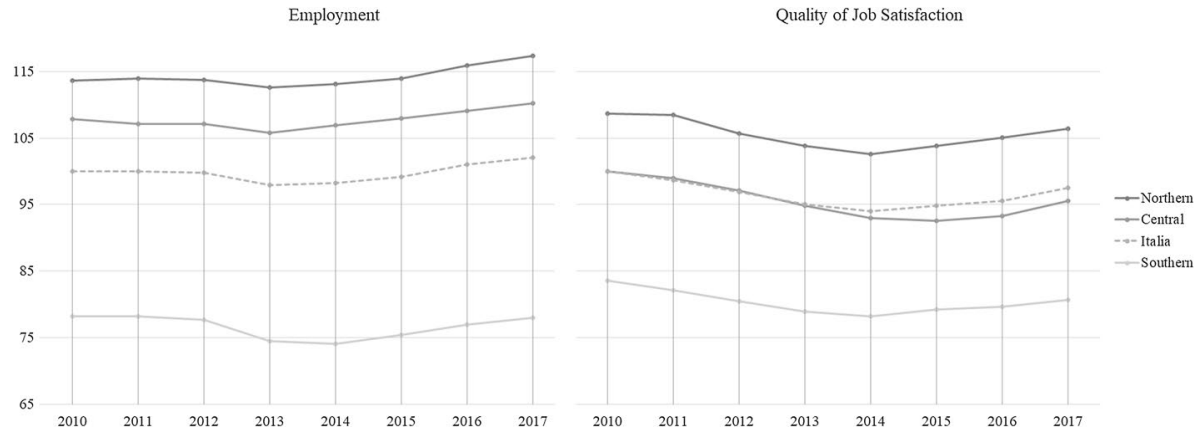

Fig. 2 Time series for the "Work and life balance" domain synthetic indices in BES

The opportunity to use well-being information for policy-makers is nowadays fundamental. In Italy, policy-makers need to operate at different geographical levels according to laws and characteristics of the different areas. For this reason, the well-being information support must include different aggregation levels. Unfortunately, the measures are often unavailable at a more disaggregated level, not allowing comparisons of disparities within the country or between different social groups (Burchi \& Gnesi,2016).

Looking at point $2 \mathrm{a}$ in Table 2, we remark that, excluding the pilot initiative of the BES that considers only $25 \%$ of the Italian provinces, the only disposable data at the NUTS 3 level ${ }^{7}$ are provided by the QoL. This lack of information for BES and BLI represents a fault of support for policy-makers that need to be felt.

\footnotetext{
${ }^{7}$ NUTS refers to the Nomenclature of Territorial Units for Statistics provided by the Eurostat, in order to apply a common statistical standard across the European Union. In Italy, NUTS 3 refers to the 107 or 110 Italian provinces, while NUTS 2 refers to the 20 Italian regions.
} 
The actual structure of the BES is performed at the NUTS 2 level (point $2 \mathrm{~b}$ in Table 2).

The regional structure permits local governors to plan their strategies and policies. In order to provide better support, the presence of synthetic indices for each dimension is desired. Since 2016, ISTAT has been working on this topic.

For the BLI, despite the presence of a regional edition, the temporal gap of the data could be misleading for the policy-maker that can arrive at incorrect decisions.

Finally, with reference to point $2 \mathrm{c}$ in Table 2, there is no Italian global BES well-being index, but for each indicator and for the provided synthetics domains indices, they propose aggregations at macro-area (Northern, Central, Southern) and National level. The macroarea values are the means of the corresponding regional area indices, analogously for the National values. Figure 2 reports the time series of the synthetic indices computed for the domain "Work and life balance". For a single macro-area, we note that time differences are not evident; instead, there are disparities among the three macro-areas: the Northern values are always greater than those of the Central and Southern, while the National time series is positioned in the intermediate zone. This result indicates a well-known geographical structure for the Italian economic situation.

The only initiative that permits having a global well-being index for Italy as a country is the OECD BLI. This allows us to compare Italian well-being with one of the other nations. Evidently, a global index could also be misleading because the variability within the different social groups is masked. In an ideal context, we should have well-being indices providing all the previous different levels of aggregation, but this is still an open challenge.

\section{Timing monitoring and control}

All three examined indices have an annual frequency, with none based on semi-annual or higher frequency time series. We are living in an era in which everything happens with great speed, and daily changes occur in everyone's life and in the communities in which we live. Consequently, it would be necessary to consider well-being changes more frequently in order to be able to keep the infra-annual trends. In an attempt to fill this gap, such indices as SWBI could be considered jointly with traditional measures.

Looking at the methodological rigour of the time series, we have already stressed that the QoL changes the used indicators and corresponding dominions in the different editions (see Tables 4 and 5). For example, going back to the time-series, "broadband coverage", traditionally in Environment and services, passed to Culture and leisure from 2013 to 2014. Furthermore, when the indicator is the same, it is sometimes detected with different measures. For instance, information about "shows" in Culture and leisure has been detected for some years as the number of shows, the number of cinemas, or the number of cinema seats per inhabitant. We remark that, on the one hand, the improving number of the indicators used in the 2019 edition (from 42 to 90 ) is a good enhancement, but on the other hand, it could be a serious problem for the meaning of the time series. In addition, no information is given about the consistency of the time series after the score assigned method shake-up (from Eq. (1) to Eq. (2)). All these quotes could prove deleterious when decisionmakers base their choices on such time-series information.

In reference to the BLI, information is almost always delayed. Considering the Italian index on the web platform in 2017 , we observe that only $21 \%$ refers to 2016 . Sometimes the measure is the 3-year average 2014-2016, and for all other indicators, there is a greater lag that, for example, for "time devoted to leisure and personal care", arrives to 18 years. 
Table 3 Time ranges for the indicators related to the different domains in the 2018 BES initiative

\begin{tabular}{llc}
\hline Domains & First & Last \\
\hline Work and life balance & 2014 & 2017 \\
Economic well-being & 2016 & 2017 \\
Education and training & 2016 & 2018 \\
Environment & 2015 & 2018 \\
Health & 2015 & 2017 \\
Landscape and cultural heritage & 2011 & 2017 \\
Politics and institutions & 2014 & 2018 \\
Service quality & 2014 & 2017 \\
Research and innovation & 2012 & 2017 \\
Security & 2014 & 2017 \\
Social relationships & 2016 & 2017 \\
Subjective well-being & 2017 & 2017 \\
\hline
\end{tabular}

To aggravate the situation of this index, essentially born for comparisons between countries, we remark that these delays change with the considered country.

Also for the BES, some information is delayed. As an example, for Health in 2015, no single indicator refers to $2015,36 \%$ refers to 2014 , and $64 \%$ is further delayed. In either case, it is important to note that in proceeding with the initiative, each year (and from 2019 also with a semestral step), the data are uploaded and revisited. This is a key aspect of the quality of the time series. Meantime we are writing, the 2019 edition has been presented, but the corresponding data are not distributed. For this reason, we refer to the 2018 edition, where the indicators utilised for each domain are timely defined, as in Table 3. We underline that only three dimensions have 2018 data, and within these, only eight indicators $(6.2 \%$ of the total) are updated to the same date.

\section{Multi-dimensional framework}

Since their birth, all the above well-being indices have had a composite structure (point $4 \mathrm{a}$ in Table 2), defined in the previous year using different domains, as described in the corresponding frameworks (Tables 5, 6 and 7). Especially for BES, the first releases offered only a simple description of the indicators related to each domain topics. The others gave form at the beginning aggregated versions.

As noted in Sect. 2.3, from 2013 to 2014, for BES, the only available aggregation was provided by IRES Piemonte, using the Penalties for the Coefficient of Variation Method (MPCV, (Mazziotta et al., 2008)). MPCV standardises the data, then for each observation, horizontally evaluate the coefficient of variation, i.e. the ratio between the horizontal standard deviation and the horizontal mean. This coefficient measures what the authors call horizontal variability. Finally, for each unit, they compute the product between the horizontal mean and the complement to one of the squares of the horizontal coefficient of variation. Therefore, the greater the horizontal mean and the lower the horizontal standard deviation, the greater is the value of the index. This allows the penalisation of unit scores, which, with the same mean, have the greatest imbalance between indicator values.

With reference to point $4 \mathrm{~b}$ in Table 2 , the recent editions of the three well-being indices are performed using different granularities and methods of aggregation. For the QoL, we remark that they compute scores for each indicator, each domain and a global well-being 
index, all at the provincial level. Nevertheless, the weights for each indicator and domain are always the same.

For the OECD initiative, they compute scores for each domain and a global well-being index. The weights for each indicator are fixed. Otherwise, for each domain it is possible to choose them following a personal system of preferences to define a global national index.

Since 2015, ISTAT has provided itself domain-specific synthetic indices by adopting the AMPI method. Specifically, for this first time, the aggregated indices were computed for only nine domains (no indices are calculated for "Politics and institutions", "Service quality" and "Research and innovation") using a fewer number of indicators than the composite. For the 2019 edition, without the data release, ISTAT declared having considered 15 synthetic indices: nine representing a single domain, and six given by three domains from which two measures are considered. For "Work and life balance", an employment index and quality of job satisfaction index are considered; for "Economic well-being" separately aggregates an income and inequality index and minimum economic level index; for the "Security" domain, they keep a separate homicides index and other crimes index. In Fig. 2, as exemplification, the time series for the employment index and the quality of job satisfaction index aggregated at macro-area and National level. We remark that the actual structure of the BES is performed at the regional level. The macro-area values are the means of the corresponding regional area indices, analogous to the National values. For both synthetic indices, the macro-area dissimilarities are greater for the employment index and smaller for the quality of job satisfaction index: for the subjective dimension, there is less variability among the geographical areas. Also in this edition, not all 130 indicators were used for the aggregations. Only 61 of them, as can be seen in Table 7. Finally, at the provincial level, we underline that the only available information comes from the composite indices because no synthetic measure is provided.

\section{Objective vs subjective dimensions}

Following the Stiglitz Commission guidelines, each well-being measure should account for a wide set of indices representing both objective and subjective assessment. While the QoL, with its huge number of indicators proposed in the 2019 edition, has no subjective or perceived items, the BLI and BES initiatives agreed with the suggestion. However, for the OECD index, less than $17 \%$ and $8 \%$ of the indicators represent subjective assessments at the national and regional level, respectively (see Table 6).

Notably, the national-level BES report takes into account both subjective and objective dimensions and, with its great number of indicators, represents a good multifaceted source of information (note that the subjective well-being is not considered in BES for the provinces and in UrBES, due to the lack of adequate statistical quality sources). However, looking at the BES's general framework, it is evident that the domains "Health", "Education and training", "Economic well-being", "Innovation, research and creativity", do not consider the subjective aspect of well-being. It would be better if every domain assesses a perceived or subjective dimension, especially for health quality, a measure concerning with these personal aspects is essential.

Finally, note that several perceived or subjective items considered, come from the "Aspect of daily life" report. This ISTAT sample survey collects fundamental details on Italian individual and household daily life. This is an annual survey; the data are distributed free of charge, the aggregation is disposable for the twenty Italian regions and five Italian geographical areas (North-west, North-east, Central, South, and Islands). A new design for 
the "Aspect of daily life" survey, including new subjective items and the provincial sampling design, should be a simple but important improvement.

\section{Conclusion}

The well-being measurement is a matter of worldwide interest; thus, several new indices have been proposed. Due to the central role given to this topic by Italian institutions, the focus of this paper shed light on the Italian well-being scenario. Similar studies should be conducted for other countries.

We described the three principle well-being indices related to total population: the "Il sole 24 ore" Quality of Life index, the Better Life index, and the Equitable and Sustainable Well-Being index. Specifically, for each index, we discussed its features, structures, coverages and availability. These well-being measures have a different history. They have been proposed for different scope and in different periods, with different theoretical, geographical and timing frameworks. Their usage should also be different; however, they are often used as substitutes or complementaries, particularly by the media.

Moreover, we propose an objective evaluation of the three considered indices. This evaluation is not a stand-alone critique, but our aim is to provide conscious knowledge since the highlighted indices' flaws are serious issues when decision-makers want to base their choices on them or the purpose is to make national or international rankings.

Looking at the features and theoretical framework, especially in light of the Stiglitz commission suggestions, there is no doubt that the only index that captures the most aspects is the BES. Nonetheless, also for this initiative, important improvements could be considered.

In order to improve the quality of well-being indices, in addition to having good knowledge for the data, it is essential to: possess better data planning, increase the time frequencies and data disaggregation as much as possible, and give more space to the subjective dimension. Looking at the features and theoretical framework, especially in light of the Stiglitz commission suggestions, there is no doubt that the only index that captures the most aspects is the BES. Nonetheless, also for this initiative, important improvements could be considered.

Practitioners are currently trying to move in this direction, combining well-being measures with other secondary data including social and/or economic information, or mostly dealing with different sources, such as new surveys, and data provided by social media or big data. This updating is essential, a challenge for positive policy planning, an aware scientific use, and a meaningful international comparison. However, this is not an easy task. It requires a general and severe review of the data collection procedures, which must be led by the well-being topic aims. Last but not least, it provides for a consequent increase of time and costs, which could be unsustainable in the current situation.

\section{Appendix}

A detailed description of the full QoL, BLI and BES framework for the 2019 editions is reported in the following three tables. 
Table 4 Description of the full QoL framework for the 2018 edition

\section{Wealth and consumption}

Bank deposits per capita-in $€$

Average selling price of houses-in $€$ per $m^{2}$

Average rental rates-in $€$ per month

Household durable goods expenditure-in $€$ per year

Protests per capita-in $€$ per year

GDP per capita

Travel/tourism consumption per capita

\section{Business and work}

Youth unemployment rate-in \% of the population aged 15-24

Export share of GDP-(exports)/(value added in 2018) in \%

Registered companies per 100 inhabitants

Number of innovative start-ups-per 1000 capital companies

Employment rate

Loans on deposits ratio

Gender salary gap

\section{Environment and services}

Social expenditure in minors, disables, elderly at local-in $€$

ICityRank-smartest city index (106 indicators)

Index on urban ecosystem

Home banking

Hydrogeological risk

Average life expectancy

Index of climatic excursion $\left(T_{\min }-T_{\max }\right)$

Demography and society

Internal migration balance-(transfers from-transfers to)

Mortality rate-standardized per 10,000 inhabitants

Birth rate-(live births)/(average residents) $x 1,000$

Elderly index-(65 and over $) /(0-14) \times 100$

Citizenship acquisitions-citizenship acquired per 100 foreigns

Resident graduates

Fertility rate

\section{Justice and security}

Car thefts-reports per 100,000 inhabitants

Robberies-reports per 100,000 inhabitants

Crimes related to drugs-reports per 100,000 inhabitants

Litigation index-civil cases registered per 100,000 inhabitants

Share of over three-year pending cases on the total-in \%

Average duration of civil lawsuits-in days

Muggings and pickpocketing

\section{Culture and leisure}

Cinemas-seats for every 100,000 inhabitants (2018)

Libraries-number every 10,000 inhabitants

Density of the cultural offer-number of shows every $10 \mathrm{~km}^{2}$

Sportiness index-final index

Tourists, average stay in accommodation facilities

Shows tickets, box office spending

Non-profit association

\section{Source}

ABI-Bank of Italy (2017)

Scenari immobiliari (N/A)

Scenari immobiliari (N/A)

Findomestic Observatory (2017)

Il Sole 24 Ore on Infocamere data (N/A)

Prometeia (2017)

Il Sole 24 Ore on Bank of Italy data (2017)

Source

ISTAT (2017)

Prometeia (2017)

Istituto Tagliacarne (2018)

Infocamere

ISTAT (2017)

ABI-Bank of Italy (2017)

Labor Consultants Observatory (2017)

Source

Istituto Tagliacarne (2017)

Index Forum PA (2018)

Legambiente (2018)

ABI-Bank of Italy (2017)

ISPRA (2017)

ISTAT (2017)

N/A (2017)

Source

ISTAT (2017)

ISTAT (2017)

ISTAT (2017)

ISTAT (2017)

ISTAT (2017)

MIUR-ISTAT (2017)

ISTAT (2017)

Source

Il Sole 24 Ore on Interior M. data (2017)

Il Sole 24 Ore on Interior M. data (2017)

Il Sole 24 Ore on Interior M. data (2017)

Il Sole 24 Ore on Justice M. data (2017)

Il Sole 24 Ore on Justice M. data (2017)

Il Sole 24 Ore on Justice M. data (2017)

Il Sole 24 Ore on Interior M. data (2017)

Source

Istituto Tagliacarne (2017)

Infocamere (2017)

SIAE (2017)

CLAS-PTS Group(2018)

ISTAT (2017)

SIAE (2017)

Income revenue authority (2018) 
Table 4 (continued)

In "Italic" the presence of the indicators in the same dominion in 2018 and 2019 editions

Table 5 Description of the full QoL framework for the 2019 edition

\section{Wealth and consumption}

Value added per inhabitant-1000 $€$ at current values

Bank deposits per capita-in $€$

Average monthly mortgage rate-in $€$

Loans-average residual exposure in $€$

Average selling price of houses-in $€$ per $m^{2}$

Average rental rates-in $€$ per month

Real estate index-( $m^{2}$ bought or sold $) /\left(\mathrm{m}^{2}\right.$ offered in 1 year $)$ in \%

Average amount of old-age pensions-in $€$ per year

Household durable goods expenditure-in $€$ per year

Protests per capita-in € per year

Average monthly installment repaid for loans-in $€$

Loan Risk-Cash loan decay rate in \%

Population with active credits-in $\%$ of the total number of adults

Average overall income per taxpayer-in $€$ per year

Change in average income of taxpayers-from 2007 to 2017 in \%

\section{Business and work}

Regular resident immigrants-in \% of the resident population

Unemployment rate-in \% of the population aged 15-74

Youth unemployment rate-in \% of the population aged 15-29

Youth entrepreneurship trend-(co. under 35) / (total co.)

Export share of GDP-(exports)/(value added in 2018) in \%

Debts index-(gross bad debts)/(loans to people and companies)

Inactivity rate-(unemployed and not seeking)/(residents) in \%

Registered companies per 100 inhabitants

Foreign companies-(foreign co.)/(total co.) in \%

E-commerce companies-(e-commerce co.)/(total co.) in \%

Broadband, 30 and $100 \mathrm{mb}$ coverage-in \%

Number of enterprises in the www-per 1000 registered enterprises

Number of innovative start-ups-per 1000 capital companies

Gender employment rate-(male-female) in 15-64 in \%

Net entry rate for co.-(registered-closed)/(previous year) in \%

Bankrupt co.-(bankrupt companies)/(total companies) in \%

\section{Environment and services}

Social expenditure in minors, disables, elderly at local-in $€$

Hospital emigration-\% of dismissals outside the region

Water purification capacity-in \%

Climate index-final index

Public transport passengers-(passengers)/(inhabitants)

Consumption of drugs for hypertension-minimum units per capita

Air quality PM10-average concentration in $m g$ per $m^{3} \mathrm{~h}$ 
Table 5 (continued)

Consumption of diabetes drugs-minimum units per capita

Municipal waste production per capita-kg per inhabitant

Separate collection-in \%

Public transport offer-(public transports km)/(inhabitants)

General practitioners-doctors active every 1,000 inhabitants

Pediatricians-doctors active per 100 inhabitants in $0-15$ years

Consumption of drugs for asthma and COPD-min units per capita

ICityRank-smartest city index (106 indicators)

\section{Demography and society}

Internal migration balance-(transfers from-transfers to)

Mortality rate-standardized for 10,000 inhabitants

Mortality (myocardial infarction)-deaths per x 1,000 in 5 years

Cancer mortality-deaths per 1,000 inhabitants in 5 years

Life expectancy at birth-age in years

Large families-average number of members per family

Increased life expectancy-increased expected age at birth

Families-households and unions per 1,000 inhabitants

Birth rate-(live births)/(average residents) $\times 1,000$

Elderly dependency index-(65 and over)/(workers in 15-64) x 100

Elderly index-(65 and over $) /(0-14) \times 100$

New AIRE members-(registered)/(canceled) per 1,000 inhabitants

Average number of years of study-for over $25 \mathrm{~s}$

Citizenship acquisitions-citizenship acquired per 100 foreigns

\section{Justice and security}

Car thefts-reports per 100,000 inhabitants

Home burglaries-reports per 100,000 inhabitants

Sexual violences-reports per 100,000 inhabitants

Crime index-reports per 100,000 inhabitants

Robberies-reports per 100,000 inhabitants

Extortions-reports per 100,000 inhabitants

Crimes related to drugs-reports per 100,000 inhabitants

Computer scams and frauds-reports per 100,000 inhabitants

Litigation index-civil cases registered per 100,000 inhabitants

Share of over three-year pending cases on the total-in \%

Average duration of civil lawsuits-in days

Rotation index of cases-(defined proceedings)/(new members)

Money laundering and use-reports per 100,000 inhabitants

Fires-reports per 100,000 inhabitants

Road accidents-killed and injured per 1,000 inhabitants

\section{Culture and leisure}

Cinemas-seats for every 100,000 inhabitants (2018)

Libraries-number every 10,000 inhabitants

Restaurants and bars-number per 100,000 inhabitants

Concert offer-number of shows per 1,000 inhabitants

Density of the cultural offer-number of shows every $10 \mathrm{~km}^{2}$

Hotel accommodation quality-average number of stars 
Table 5 (continued)

Sportiness index-final index

Number of bookstores-per 100,000 inhabitants

Number of gyms-per 100,000 inhabitants

Per capita expenditure on shows-in $€$ per year

Ultra-broadband penetration-residents subscriptions in \%

Sports and nature index-golf courses, diving centers, etc .

Sports and children index-children in CONI federations or schools

Exhibition offerings-number of shows per 1,000 inhabitants

Density of beds in accommodations-beds per square $\mathrm{km}$

In "Italic" the presence of the indicators in the same dominion in 2018 and 2019 editions

Table 6 Description of the full BLI framework from the 2019 web platform

\begin{tabular}{|c|c|c|}
\hline Domains & National Indicators & Regional Indicators \\
\hline \multicolumn{3}{|l|}{ Quality of life } \\
\hline Health status & $\begin{array}{l}\text { Life expectancy at birth (2016) } \\
\text { Self-reported health status (2016) }\end{array}$ & $\begin{array}{l}\text { Life expectancy at birth (2016) } \\
\text { Mortality rate (2016) }\end{array}$ \\
\hline Work-life balance & $\begin{array}{l}\text { Time devoted to leisure (2013-14) } \\
\text { Employees working very long hours } \\
\text { (2017) }\end{array}$ & N/A \\
\hline Education and skills & $\begin{array}{l}\text { Educational attainment (2017) } \\
\text { Students cognitive skills (PISA-2015) } \\
\text { Years in education (2016) }\end{array}$ & Educational attainment (2017) \\
\hline Civic engagement & $\begin{array}{l}\text { Voter turnout (2018) } \\
\text { Consultation on rule making (2017) }\end{array}$ & Voter turnout (2017) \\
\hline Environmental quality & $\begin{array}{l}\text { Air quality (2013) } \\
\text { Satisfaction with water quality (2014-17) }\end{array}$ & Air quality (2015) \\
\hline Personal security & $\begin{array}{l}\text { Homicide rate (2015-17) } \\
\text { Self-reported victimization }(2015-17)\end{array}$ & Homicide rate (2013) \\
\hline Accessibility of services & N/A & Broadband connection (2017) \\
\hline Social connections & Social network support (2015-17) & Social network support (2010) \\
\hline Life satisfaction & Life satisfaction $(2015-17)$ & Life satisfaction (2010) \\
\hline Material conditions & & \\
\hline Income and wealth & $\begin{array}{l}\text { Household net adjusted disposable } \\
\text { income (2016) } \\
\text { Household net financial wealth (2014) }\end{array}$ & Household disposable income (2016) \\
\hline Jobs and earnings & $\begin{array}{l}\text { Employment rate (2017) } \\
\text { Long-term unemployment rate (2017) } \\
\text { Average annual earnings per employees } \\
\quad(2017) \\
\text { Job security (2015) }\end{array}$ & $\begin{array}{l}\text { Employment rate (2017) } \\
\text { Unemployment rate (2017) }\end{array}$ \\
\hline Housing & $\begin{array}{l}\text { Number of rooms per person (2012-17) } \\
\text { Housing expenditure (2014) } \\
\text { Dwellings without basic facilities (2012- } \\
\text { 17) }\end{array}$ & Number of rooms per person (2011) \\
\hline
\end{tabular}

In "Italic" the perceived or subjective items 
Table 7 Description of the full BES framework for the 2019 edition

Regional Indicators $\quad$ Provincial Indicators

\section{Health}

*Life expectancy at birth (2018)

*Healthy life expectancy at birth (2018)

Mental Component Summary (2018)

Infant mortality rate (2016)

Road accidents mortality rate (15-34) (2018)

Cancer mortality rate (20-64) (2016)

Dementia and NSD mortality rate $>65$ (2016)

*Life expectancy without limitations (2018)

Overweight or obesity (2018)

Smoking (2018)

Alcohol consumption (2018)

Sedentariness (2018)

Nutrition (2018)

\section{Education and training}

*Participation in early childhood education (2017/18)

*Upper secondary education level (25-64) (2018)

*High education level (30-34) (2018)

University entry rate $(2018 / 19)$

*Early leavers from education and training (2018)

NEET (2018)

*Participation in long-life learning (2018)

Level of literacy (2018/19)

Level of numeracy (2018/19)

People with high level of IT competencies (2019)

Cultural participation index (2018)

\section{Work and life balance}

**Employment rate (20-64) (2018)

Non-participation rate (2018)

Employment transition rate (2017/18)

*Temporary jobs rate (at least 5 years) (2018)

*Hourly earning rate (below 2/3 of median) (2018)

Over-qualified employed rate (2018)

Incidence rate for occupational injuries (2017)

*Non regular occupation rate (2016)

Women WOW children 0-5 employment rate (2018)

Over 60 h/week working rate (15-64) (2013/14)

Women household working rate (2013/14)

*Job satisfied rate (2018)

Insecure working rate (2018)

*Involuntary part time (2018)

\section{Economic well-being}

**Per capita adjusted disposable income (2017)
Female life expectancy at birth

Male life expectancy at birth

Life expectancy at birth

Road accidents mortality rate (15-34)

Cancer mortality rate

Dementia and NSD mortality rate

Participation in long-life learning

Upper secondary education level (25-64)

High education level (30-34)

NEET

Level of literacy

Employment rate (20-64)

Non-participation rate (15-74)

Non-participation rate (15-24)

Gender balance in non-participation rate

Gender employment rate (f/m)

Employment rate (15-29)

Incidence rate for occupational injuries

Paid working days for employed

Unemployment rate (15-74)

Unemployment rate (15-29) 
Table 7 (continued)

Regional Indicators

** Disposable income inequality (2017)

People at risk of poverty (2017)

Per capita net wealth (2016)

Financial vulnerability rate (2016)

Absolute poverty rate (2018)

*Severe material deprivation rate (2018)

${ }^{*}$ Severe housing deprivation rate (2018)

*Index of economic distress (2018)

*Low work intensity (2018)

\section{Social relationships}

* Satisfaction with family relations (2018)

* Satisfaction with friends relations (2018)

*People to rely on (2018)

*Social participation (2018)

${ }^{*}$ Civic and political participation (2018)

*Voluntary activity (2018)

*Association funding (2018)

No-profit organizations (2017)

* Generalized trust (2018)

\section{Politics and institutions}

Voter turnout (2019)

*Trust in the parliament (2018)

*Trust in judicial system (2018)

*Trust in political parties (2018)

${ }^{*}$ Trust in police and fire department (2018)

Parliament women political representation (2018)

*Regional women political representation (2019)

Women in decision-making organizations (2019)

Women in stock exchange co. boards (2019)

Average age of members of Parliament (2018)

*Average duration of civil lawsuits (2018)

*Prison density (2018)

\section{Security}

**Homicide rate (2018)

*Burglary rate (2018)

*Pick-pocketing rate (2018)

*Robbery rate (2018)

Physical violence rate on women (2014)

Sexual violence rate on women (2014)

Intimate couple violence rate (2016)

Worries of being victim of a sexual violence (2016)

Perceived security rate (2016)

Perceived crime rate (2016)
Provincial Indicators

Annual average pay for employed

Low retirement benefits

Gender employment salary rate $(\mathrm{f} / \mathrm{m})$

Notified eviction

Bank bad loans entry rate

Average retirement benefits

Nation schools with internal accessible way Nation schools with external accessible way Private schools with internal accessible way Private schools with external accessible way Handicapped students

Handicapped students in secondary schools Residency permit rate

Non-profit institutions

City women political representation City young $<40$ political representation Internal financial rate in provincial admin Internal financial rate in city admin City tax collecting power Provincial tax collecting power

Homicide rate

Crime reports

Extreme crime reports

Common crime reports

Deaths in 100 car crashes

Deaths in 100 suburban car crashes 
Table 7 (continued)

Regional Indicators

Provincial Indicators

Social decay (or incivilities) rate (2016)

\section{Subjective well-being}

* Life satisfaction (2018)

Leisure time satisfaction (2018)

Positive judgement for future perspectives (2018)

Negative judgement of future perspectives (2018)

\section{Landscape and cultural heritage}

*City heritage current expenditure (2017)

National museums guests

Density and importance of museums' heritage (2017)

*Illegal building rate (2018)

Erosion of farmland from urban sprawl (2011)

Erosion of farmland from abandonment (2011)

Mining and quarrying burden (2017)

Impact of forest fires (2018)

*Rural tourism facilities rate (2018)

Historical green spaces rate (2018)

*Dissatisfaction for landscape near home (2018)

Concern about landscape deterioration (2018)

\section{Environment}

Emissions of CO2 and other greenhouse gasses (2018)

Domestic material consumption (2017)

*Water losses in urban supply system (2015)

*Landfill of waste (2018)

*Quality of urban air-PM10 (2018)

*Quality of urban air-nitrogen dioxide (2018)

Quality of marine coastal waters (2018)

*Urban green (2018)

*Satisfaction for the environment (2018)

Contaminated sites (2018)

Areas with landslide risks (2017)

Areas with hydrogeological risks (2017)

Sewage treatment (2015)

*Protected natural areas (2017)

Concern for biodiversity loss (2018)

*Energy from renewable sources (2017)

*Separate collection in urban waste (2018)

Waterproofing ground rate (2018)

\section{Innovation, research and creativity}

*R\&D intensity (2017)

Patent propensity (2016)

*Employment rate with R\&D skills (2018)

Innovation rate of the national manufacturing (2016)

Intellectual property rate (2018)

Urban green

Irregularities in water supply

Household electric power consumption

Landfill of waste

Quality of urban air-PM10

Quality of urban air-nitrogen dioxide

Energy from renewable sources
Productivity specialization in R\&D

Patent propensity

Patents in high-tech

Patents in ICT

Patents in biotechnologies 
Table 7 (continued)

\begin{tabular}{ll}
\hline Regional Indicators & Provincial Indicators \\
\hline${ }^{*}$ Cultural employment (2018) & Brain migration rate (25-39) \\
Brain migration rate (25-39) (2018) & \\
Quality of services & \\
*Beds in residential health care facilities (2016) & Health emigration \\
${ }^{*}$ Local childhood services rate (2016/17) & Local childhood services rate \\
Elderly assistance service rate (2018) & Separate collection in urban waste \\
*Service accessibility rate (mean 2016-18) & Prison density \\
Broadband coverage (2015) & Breaks in electric city power \\
${ }^{*}$ Irregularities in water supply (2018) & Seats-Km of public transport networks \\
Irregularities in electric power distribution (2018) & \\
$*$ Seats-Km of public transport networks (2017) & \\
Time for daily mobility (2013/14) & \\
$*$ Mobility satisfaction (2018) & \\
\hline
\end{tabular}

In "Italic" the perceived or subjective items, the symbol "**" is used for the items considered in the aggregation for the synthetic index, while the symbol "**" is used for the items considered in a second synthetic index in the same domain

Funding Open access funding provided by Università Cattolica del Sacro Cuore within the CRUI-CARE Agreement.

Open Access This article is licensed under a Creative Commons Attribution 4.0 International License, which permits use, sharing, adaptation, distribution and reproduction in any medium or format, as long as you give appropriate credit to the original author(s) and the source, provide a link to the Creative Commons licence, and indicate if changes were made. The images or other third party material in this article are included in the article's Creative Commons licence, unless indicated otherwise in a credit line to the material. If material is not included in the article's Creative Commons licence and your intended use is not permitted by statutory regulation or exceeds the permitted use, you will need to obtain permission directly from the copyright holder. To view a copy of this licence, visit http://creativecommons.org/licenses/by/4.0/.

\section{References}

Bai, X., Nath, I., Capon, A., Hasan, N., \& Joron, D. (2012). Health and wellbeing in the changing urban environment: Complex challenges, scientific responses, and the way forward. Current Opinion in Environmental Sustainability, 4, 465-472.

Banai, R., \& Rapino, M. (2009). Urban theory since a theory of good city form (1981): A progress review. Journal of Urbanism: International Research on Placemaking and Urban Sustainability, 2, 259-276.

Barrington-Leigh, C., \& Escande, A. (2018). Measuring progress and well-being: A comparative review of indicators. Social Indicator Research, 135, 893-925.

Burchi, F., \& Gnesi, C. (2016). A review of the literature on well-being in Italy: A human development perspective. Forum for Social Economics, 45, 170-192.

Ceron, A., Curini, L., \& Iacus, S. (2016). iSA: A fast, scalable and accurate algorithm for sentiment analysis of social media content. Information Sciences, 367-368, 105-124.

Curini, L., Iacus, S., \& Canova, L. (2015). Measuring idiosyncratic happiness through the analysis of twitter: An application to the italian case. Social Indicators Research, 2, 525-542.

De Mauro, P., Mazziotta, M., \& Pareto, A. (2011). Composite indices of development and poverty: An application to MDGs. Social Indicators Research, 104, 1-18.

Dodds, P., Harris, K., Kloumann, I., Bliss, C., \& Danforth, C. (2011). Temporal patterns of happiness and information in a global social network: Hedonometrics and twitter. PLOS ONE, 6, 1-26.

Fleurbaey, M. (2009). Beyond gdp: The quest for a measure of social welfare. Journal of Economic Literature, 47, 1029-75. 
Foster, S., \& Wall, T. (2019). Organizational initiatives for spiritual well-being. Cham: Springer.

Hagerty, M., Cummins, R., Ferriss, A., Land, K., Michalos, A., Peterson, M., et al. (2001). Quality of life indexes for national policy: review and agenda for research. Social Indicator Research, 55, 1-96.

Hofacker, C. F., Malthouse, E. C., \& Sultan, F. (2016). Big data and consumer behavior: Imminent opportunities. Journal of Consumer Marketing, 33(2), 89-97. https://doi.org/10.1108/JCM-04-2015-1399.

Iacus, S. M., Porro, G., Salini, S., \& Siletti, E. (2015). Social networks, happiness and health: From sentiment analysis to a multidimensional indicator of subjective well-being. arXiv:1512.01569

Iacus, S. M., Porro, G., Salini, S., \& Siletti, E. (2019). Social networks data and subjective well-being. An innovative measurement for Italian provinces. Italian Journal of Regional Studies, 18, 667-678.

Iacus, S. M., Porro, G., Salini, S., \& Siletti, E. (2020). Controlling for selection bias in social media indicators through official statistics: A proposal. Journal of Official Statistics, 36, 315-338.

ISTAT. (2019). BES 2019 Il benessere equo e sostenibile in italia. https://www.istat.it/it/files//2019/12/Bes_ 2019.pdf.

Ivaldi, E., Bonatti, G., \& Soliani, R. (2014). Composite index for quality of life in Italian cities: An application to URBES indicators. Review of Economics and Finance, 4, 18-32.

Kasparian, J., \& Rolland, A. (2012). Oecd's "better life index"': Can any country be well ranked? Journal of Applied Statistics, 39, 2223-2230.

Khatri, P., \& Gupta, P. (2017). Workplace spirituality: A predictor of employee wellbeing. Asian Journal of Management, 8, 284-292.

Kwong, B. M., McPherson, S. M., Shibata, J. F. A., \& Zee, O. T. (2012). Facebook: Data mining the world's largest focus group. Graziadia Business Review, 15, 1-8.

Lun, G., Holzer, D., Tappeiner, G., \& Tappeiner, U. (2006). The stability of rankings derived from composite indicators: Analysis of the "il sole 24 ore" quality of life report. Social Indicators Research, 77(2), 307-331.

Mazziotta, C., Mazziotta, M., Pareto, A., \& Vidoli, F. (2008). La costruzione di un indicatore sintetico di dotazione infrastrutturale: metodi ed applicazioni a confronto. Bari: Atti della XXVIII Conferenza Italiana di Scienze Regionali AISRe.

Mazziotta, M., \& Pareto, A. (2007). Un indicatore sintetico di dotazione infrastrutturale: il metodo delle penalitá per coefficiente di variazione. in lo sviluppo regionale nell'unione europea-obiettivi, strategie, politiche. Atti della XXVII Conferenza Italiana di Scienze Regionali AISRe, Bolzano.

Mazziotta, M., \& Pareto, A. (2016). On a generalized non-compensatory composite index for measuring socio-economic phenomena. Social Indicators Research, 127, 983-1003.

New Economics Foundation. (2012). The Happy Planet Index: 2012 report. A global index of sustainable well-being. The New Economics Foundation (NEF).

Nissi, E., \& Sarra, A. (2018). A measure of well-being across the italian urban areas: An integrated deaentropy approach. Social Indicator Research, 136, 1183-1209.

OECD. (2011). How's life? measuring well-being. https://www.oecd-ilibrary.org/economics/how-s-life_ 9789264121164-en.

OECD. (2013). How's life? measuring well-being. https://www.oecd-ilibrary.org/economics/how-s-life2013_9789264201392-en.

Pentland, A. (2014). Social physics: How good ideas spread-the lessons from a new science. Scribe Publications.

Rondinella, T., Itay-Sarig, A., Ricci, C., Segre, E., \& Zola, D. (2014). The role of civil society and regionalism for progress in well-being measurement projects-insights from international case studies. Project Wealth Local Sustainable Economic Development Research Group Working Papers.

Schwartz, H., Sap, M., Kern, M., Eichstaedt, J., Kapelner, A., Agrawal, M., Blanco E., Dziurzynski, L., Park, G., Stillwell, D., Kosinski, M., Selingman, M., \& Ungar, L. (2016). Predicting individual wellbeing through the language of social media. Pacific Symposium on Biocomputing, 21, 516-527.

Segre, E., Rondinella, T., \& Mascherini, M. (2011). Well-being in Italian regions measures, civil society consultation and evidence. Social Indicators Research, 102(1), 47-69.

Sen, A. (2003). Development as capability expansion. Readings in human development. Oxford: Oxford University Press.

Stiglitz, J., Sen, A., \& Fitoussi, J. (2009). Report of the Commission on the Measurement of Economic Performance and Social Progress (CMEPSP).

Publisher's Note Springer Nature remains neutral with regard to jurisdictional claims in published maps and institutional affiliations. 